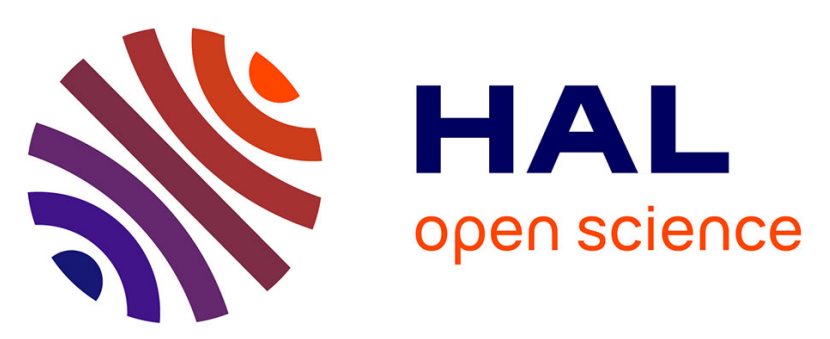

\title{
Elementary Schoolchildren's Perceived Competence and Physical Activity Involvement: The Influence of Parents' Role Modelling Behaviours and Perceptions of their Child's Competence
}

Julien Bois, Philippe Sarrazin, Robert Brustad, David Trouilloud, François Cury

\section{To cite this version:}

Julien Bois, Philippe Sarrazin, Robert Brustad, David Trouilloud, François Cury. Elementary Schoolchildren's Perceived Competence and Physical Activity Involvement: The Influence of Parents' Role Modelling Behaviours and Perceptions of their Child's Competence. Psychology of Sport and Exercise, 2005, 6, pp.381-397. 10.1016/j.psychsport.2004.03.003 . hal-00389001

\section{HAL Id: hal-00389001 https://hal.science/hal-00389001}

Submitted on 27 May 2009

HAL is a multi-disciplinary open access archive for the deposit and dissemination of scientific research documents, whether they are published or not. The documents may come from teaching and research institutions in France or abroad, or from public or private research centers.
L'archive ouverte pluridisciplinaire $\mathbf{H A L}$, est destinée au dépôt et à la diffusion de documents scientifiques de niveau recherche, publiés ou non, émanant des établissements d'enseignement et de recherche français ou étrangers, des laboratoires publics ou privés. 
1 Running Head: PARENTAL INFLUENCE ON PHYSICAL ACTIVITY

2

\section{Elementary Schoolchildren's Perceived Competence and Physical Activity}

Involvement: The Influence of Parents' Role Modelling Behaviours and Perceptions of

their Child's Competence

\section{Psychology of Sport and Exercise, 6, 381-397}

Julien E. Bois and Philippe G. Sarrazin

University of Grenoble, France

Robert J. Brustad

University of Northern Colorado, USA

David O. Trouilloud

University of Grenoble, France

François Cury

University of Marseille, France

Julien Bois, Philippe Sarrazin, and David Trouilloud are with the Laboratory 'Sport et Environnement Social' E.A. 540, UFRAPS - Université J. Fourier, Grenoble. Robert Brustad is in the School of Sport and Exercise Science at the University of Northern Colorado. François Cury is in the Faculty of Sport Sciences at the University of Marseille. This study was facilitated by a grant from two French sport organizations: the 'Direction Départementale de la Jeunesse et des Sport 26' and the 'Comité Départemental Olympique et Sportif de la Drôme'.

Correspondence:

Dr. Philippe Sarrazin, 'Laboratoire Sport et Environnement Social' E.A. 540, UFRAPS Université J. Fourier, Grenoble I. BP 53 - 38041 Grenoble Cedex 9 - France

Phone: $0033(0) 475781552$

Fax: $0033(0) 475781554$

E-mail: philippe.sarrazin@ujf-grenoble.fr 
Abstract

2 Objectives. To study the influence of fathers' and mothers' physical activity involvement

3 and perceptions of their children's physical competence upon children's perceptions of

4 competence and children's time spent in physical activity. Two forms of parental

5 socialization influence were assessed: the direct influence of parents' actual physical

6 activity (PA) behaviour (role modelling) on children's physical activity and the indirect

7 influence of parents' beliefs systems about their children's PA competence on children's

8 physical activity through children's self perceptions.

9 Method. Longitudinal, with data from 152 French children $(M=9.5$ yrs., $S D=0.8$ yrs. $)$ and

10 their parents collected at two times over a 12-month period and examined through

11 structural equation modelling (SEM).

12 Results. SEM indicated that mothers' role modelling behaviour had a direct effect on children's time spent in PA and that mothers' beliefs about their child's competence had an indirect effect on children's PA by influencing children's perceived competence which, in turn, contributed to children's level of physical activity involvement. Fathers' beliefs

16 directly influenced their child's PA as did the children's own self-perceptions of 17 competence.

18 Conclusions. Parents can affect their children's PA involvement in direct and indirect manners through their role modelling of physical activity and through their beliefs about their child's competence. Furthermore, the influence of fathers and mothers may be 21 manifested in different ways. Father and mother could influence their child's PA by 22 different processes.

24 KEY WORDS: children's physical activity, parental socialization, role modelling, perceived competence, parental beliefs, motivation. 
1 The role of physical activity (PA) in contributing to the physical, psychological, and social

2 health and development of children cannot be underestimated. Research has demonstrated

3 a moderate association between PA levels and physical health variables for children.

4 Physically active children tend to have lower blood pressure levels and more favourable

5 blood lipid profiles than sedentary children (e.g., Suter \& Hawes, 1993). Moreover, active

6 participation in sport and exercise has beneficial social and psychological effects, such as

7 increased social acceptance (e.g., Weiss \& Duncan, 1997), and elevated self-esteem and

8 feelings of well-being (e.g., Martinsen \& Stephens, 1994). In addition, research suggests

9 that PA levels during childhood could partially predict PA levels in adulthood (e.g., Sallis

10 et al., 1992). Therefore, increasing PA during childhood carries with it numerous physical,

11 psychological, and social benefits.

Researchers have initiated attempts to identify the factors that shape children's PA behaviour (e.g., Sallis \& Hovell, 1990; Sallis et al., 1992). A complex arrangement of influences seems to be involved, among which several social sources of influence clearly impact children's PA and sport involvement. These include peers, coaches/teachers and parents (see Brustad, Babkes, \& Smith, 2001). As a starting point, socialization within the family (i.e., parents and siblings) should be a fundamental form of influence because the family constitutes an important initial element of socialization influence for children and because the majority of children's free time prior to adolescence is spent within the context of the family (Brustad, 1992; Greendorfer, 1992). Unfortunately, only a limited amount of research has examined how parents influence children's PA behaviour, and some of this research suffers from methodological problems that affect our interpretation of findings.

24 frequently studied relate to parental role modelling practices and parental belief systems, particularly parental perceptions of children's competence. Role modelling, or children's 
1 vicarious identification with their parents (Bandura, 1986), has been proposed as a form of

2 influence whereby children reproduce the behaviours of their parents through observational

3 and social learning processes. Studies that have tested this hypothesis in the PA domain

4 have found mixed results. Some investigations have found a moderate to strong

5 relationship between the PA involvement of parents and their children (e.g., Freedson \&

6 Evenson, 1991; Moore et al., 1991) whereas other studies have found weak or no

7 relationships between activity levels of parents and children (e.g., Brustad, 1993; Dempsey,

8 Kimiecik, \& Horn, 1993; Kimiecik \& Horn, 1998). These discrepant findings may be a

9 function of differences in measures, such as objective indicators, children's perceptions,

10 and parents' self-reports (Fredericks \& Eccles, 2004). Therefore, it seems important to

11 design studies that use methods that are capable of providing a strong test for the effects of

12 parental role modelling on children's physical activity involvement.

Parental belief systems can also constitute an important form of socialization

influence on children's physical activity involvement. The relation between parents' beliefs and children's motivation and achievement has been well established in the educational literature (e.g., Eccles, Wigfield, \& Schiefele, 1998). According to the parental socialization model of Eccles and her colleagues (see Eccles, et al., 1998; Fredericks \&

18 Eccles, 2004), the beliefs that parents hold for their children influence their patterns of interaction with the child, such as extent of encouragement and the provision of opportunities and experiences that, in turn, affect their children's motivation. Important components of parental belief systems include parents' perceptions of the child's competencies in various achievement domains, parents' beliefs about the relative value or importance of various achievement domains (e.g., academics, art, music, sport), and parents' expectations that their child will attain success in a given domain. As proposed by Eccles and colleagues (e.g., Eccles, et al.1983; Fredericks \& Eccles, 2004; 
1 Wigfield \& Eccles, 2000), parental beliefs about their child's physical competence can

2 shape their children's activity choices indirectly through effects on the children's own

3 perceptions of competence and perceptions about the relative value of various activities.

4 Given that competence perceptions assume a central role in contemporary theoretical

5 frameworks on motivation (e.g., Bandura, 1997; Harter, 1981), and as perceived physical

6 competence has been among the most studied self-perception variables for the purpose of

7 understanding individual differences in motivated behaviour (Weiss \& Ebbeck, 1996),

8 understanding how children form competence perceptions in the physical domain is a

9 primary focus of this study. In extending Eccles' theory to the physical domain, it is

10 anticipated that parents are likely to influence their children's time spent in PA indirectly

11 by shaping children's domain-specific self-perceptions of competence which, in turn,

12 influence children's PA involvement.

13 Several studies have revealed a correspondence between parents' perceptions of

14 their child's competence and the child's own perceived physical competence (e.g., Babkes

15 \& Weiss, 1999; McCullagh, Matzkanin, Shaw, \& Maldonado, 1993), even in cases in

16 which actual levels of physical ability were statistically controlled (Bois, Sarrazin, Brustad,

17 Trouilloud, \& Cury, 2002; Felson \& Reed, 1986). However, some limitations to these

18 studies have to be acknowledged. To support the presence of a relation between parents'

19 perceptions of their child's competence and the child's perceived physical competence,

20 longitudinal designs, including autoregressive influence, are necessary (MacCallum \&

21 Austin, 2000). That is, if it is hypothesized that variable A at time 1 (A1; e.g., parent's

22 perception of child's ability) influences variable B at time 2 (B2; e.g., child's self-

23 perception of ability), the child's initial perceived competence (B1) also should be

24 measured and included in the model to understand the relation between B1 on B2 as well

25 as the relation between A1 and B1 (Gollob \& Reichardt, 1991). But much previous work 
1 has been cross-sectional in nature, making causal interpretation problematic, or did not

2 include the autoregressive effect (Jacobs \& Eccles, 1992).

Another consideration with previous studies has been that children's perceptions of parental beliefs have been relied upon rather than parents' own self-reports (e.g., Babkes \& Weiss, 1999; Brustad, 1996; Kimiecik et al., 1996). An advantage of the traditional approach is that children are likely to act upon their perceptions of their parents' beliefs as they may not effectively interpret their parents' actual beliefs. However, from a measurement standpoint, the reliance on self-reports from single sources can be problematic, in that the associations identified might be due to shared method variance rather than to actual relations involving the construct of interest. In line with that concern, a final limitation pertains to the fact that parental influence often is assessed without distinguishing between the mother's and the father's beliefs (e.g., Brustad, 1993, 1996; Dempsey et al., 1993). Fathers and mothers might not share similar appraisals of their child's aptitudes and abilities and it is likely that one parent might be more influential in shaping the child's achievement-related beliefs than the other. Because mothers typically are more fully immersed in the rearing of their children during childhood and early adolescence, mothers' perceptions might be particularly important in shaping children's achievement-related beliefs, even in stereotypically masculine achievement domains such as sport (Jacobs \& Eccles, 1992).

\section{The Present Study}

The main purpose of this study was to investigate the extent to which parents' PA behaviours and beliefs about their child's physical competence could predict the child's own self-perceptions of competence and the amount of time their child dedicated to physical activity. 
Methodological precautions were taken in order to appropriately examine socialisation processes. As parental socialisation influence needs time to operate, a 12month longitudinal study was conducted with data collected at two points in time.

Structural equation modelling (SEM) was used to determine whether theoretically anticipated relationships existed. SEM, which is particularly useful in longitudinal research (Bentler, 1980; MacCallum \& Austin, 2000), allows for examination of hypothesized relations among all of the constructs involved in a model, using a latent representation of these constructs that is less vulnerable to measurement errors, such as those that can be encountered in research with child populations.

Figure 1 shows the hypothesized model that is partly based on the Eccles et al. model of achievement-related choice (e.g., Eccles et al., 1983; Wigfield \& Eccles, 2000). In the proposed model, parents' PA is presumed to directly affect their child's involvement in PA through a role modelling effect (the dotted lines in Figure 1). Parental beliefs about their child's physical competence are also presumed to indirectly shape the time that their child spends in PA through an effect on the child's perceived physical competence (the double lines in Figure 1), controlling for the child's initial level of perceived physical competence (the auto-regressive effect). In turn, children's perceived physical competence is expected to predict their own PA involvement (the thick line in Figure 1). Gender differences were also expected (the thin lines in Figure 1). In accordance with previous research, it was anticipated that boys would report higher levels of perceived competence than would girls (e.g., Eccles \& Harold, 1991; Jacobs, Lanza, Osgood, Eccles, \& Wigfield, 2002), as well as higher levels of involvement in PA (e.g., Dempsey et al., 1993; Eccles \& Harold, 1991). Age was added as a control variable in the event that differences in the variables included in the model were affected by age-related factors. 
Another objective was to compare the specific predictive influence of mothers and

2 fathers with regard to two hypothesized forms of influence - role modelling and parental

3 beliefs - in order to determine if one of the parents would have a greater influence than the

4 other, or if the influence of the two parents was additive. In contrast with some previous

5 studies (e.g., Brustad, 1996; Kimiecik et al., 1996), fathers' and mothers' self-reports were

6 both used to reduce the shared variance problems caused by the use of children's

7 perceptions of parental beliefs.

8

9

Method

\section{Participants}

A sample of 152 intact families (mother, father and child), coming from three French cities (each with a population of 15,000 to 30,000 inhabitants), was used in this study. Only one child per family was included (no siblings participated). No child in the sample had medical or disability-imposed restrictions on physical activity. The 84 girls and 68 boys who participated ranged in age from 9 to 11 years of age $(M=9.56, S D=0.84$ yrs $)$ at the beginning of the study, their mothers averaged 38.04 years of age $(S D=3.71)$ and their fathers 39.8 years of age $(S D=4.36)$. Thirty-six of the child participants ( 16 boys and 20 girls) were between 8.5 and 9.0 years of age, 69 (30 boys and 39 girls) were between 9 and 10 years of age, and 47 ( 22 boys and 25 girls) were between 10 and 11 years of age. The sample was comprised primarily of Caucasian French middle to upper class families.

\section{Measures}

Child's perceived competence in physical activity. This construct was assessed through a French version (Sarrazin, Bois, \& Trouilloud, 2000a) of Harter's (1985) Perceived Physical Competence Scale for Children. The back-translation method (see Brislin, 1986) was used to translate the original scale into French. Items were scored on a 4-point response format using Harter's (1985) structured alternative approach. An example of one of the four items 
1 used in this scale is, "Some kids are sure that they are good at sports but other kids don't

2 think they are good at sport". On this scale, a score of 1 reflects a low level of perceived

3 physical competence and 4 a high level of perceived physical competence; scores of 2 and

43 indicate intermediate levels. In previous research, this scale has been found to be valid

5 and reliable (Bois et al., 2002; Sarrazin et al., 2000a). In the present study, the internal

6 consistency was satisfactory (Cronbach $\alpha=.72$ and .79, respectively for Time 1 and Time

$72)$

8 Child's physical activity duration. Time spent in moderate-to-vigorous-physical activity

9 was assessed at Time 2 with two complementary measures: (1) parents' reports of their

10 child's PA and (2) an interviewer-administered recall of PA for children. Previous studies

11 (e.g., Haaro, 1997; Manios, Kafatos, \& Markakis, 1998) have found that parental reports

12 are reliable and valid tools in assessing a child's moderate to vigorous physical activity.

13 Furthermore, Sallis and Saelens' (2000) review provided support for the validity of

14 interviewer-administered recall with young children.

15 Based on an adaptation of previously used methods that have demonstrated

16 reliability and validity (e.g., Kimiecik et al., 1996; Sallis, Buono, Roby, Micale, \& Nelson,

17 1993), the measures were designed to assess the duration of each child's PA involvement

18 over a one-week period, in this case the week immediately prior to the interview. Some

19 evidence (e.g., Sallis et al., 1993) indicates that younger children can report their vigorous

20 activities with reasonable accuracy, even over a 7-day period. Nevertheless, because recall

21 of PA is a complex cognitive task, especially for children (Baranowski, 1988), several

22 procedures to aid recall were used (the detailed interviewer manual is available from the

23 first author). Essentially, the procedure consisted of presenting to the child (and each

24 parent) a list of activities in which children of this age are commonly engaged. Those

25 activities included rollerblading, cycling, playing games (such as tag), rope jumping, 
1 dancing, running, skateboarding, climbing activities and sport (typical activities such as

2 soccer, basketball or rugby were given as examples), as well as an 'other' category for any

3 activities in which the children engaged that were not present on the list. Activities were

4 selected in such a way as to be representative of the age and culture of the children. The

5 protocol focused on relatively intensive activities (i.e., moderate to vigorous physical

6 activity) that should be more easily recalled than would be low intensity activities (Sallis et

7 al., 1993). For this purpose, the child was asked to identify the activities that were hard

8 enough to make her/him get tired or breathe hard or sweat. After the children were

9 reassured that it was acceptable to report no physical activity if this were accurate in their

10 case, the next step consisted in identifying any activities in which they had engaged in

11 during each day of the week. To simplify the interview, activities were counted only if they

12 totalled at least 10 continuous minutes. Then for each identified activity, children (and parents) indicated how long they were engaged. To provide them with a frame of reference, children were asked beforehand to name events that last approximately 10 minutes in duration (e.g., recess), 30 minutes in duration (e.g., school meals), etc. The interviewer assisted each child in estimating the amount of time spent in each activity on each day. The one-on-one interviews with the children lasted 10 to 15 minutes. The daily totals were summed to obtain a score representing the amount of the child's PA time in hours during the one week period. A one month test-retest correlation was conducted on a pool of 30 children and revealed satisfactory reliability for this measure $(r=.68)$. Moreover, the

21 correlation of this measure with the parents' recall measurement of their child's physical

22 activity was significant $(r=.46, p<.001)$ supporting the validity of the child's measurement. Because mothers' and fathers' reports of their children's exercise behaviour were highly correlated $(r=.98)$, they were averaged. 
1 Parental perceptions. Parental perceptions related to their child's ability in PA were

2 measured by a French version (Sarrazin, Bois, \& Trouilloud, 2000b) of Jacobs and Eccles'

3 (1992) questionnaire on mothers' perceptions of their child's physical competence. The

4 back-translation method (Brislin, 1986) was used to translate this 4-item scale into French.

5 A sample item was "In general how good is your child in sport?" This 5-point Likert-type

6 scale ranged from 1 ("not good at all") to 5 ("very good"). In previous research, this scale

7 has been found to be valid and reliable (Bois et al., 2002; Sarrazin et al., 2000b). In the

8 present study, the internal consistency was satisfactory $(\alpha=.75$ and .79 , respectively for

9 mothers and fathers).

10 Parents' physical activity. Parents' PA was measured with a one-week recall format

11 similar to the one parents used to evaluate their child's physical activity. Each parent was

12 presented a list of activities and had to identify the activities in which they participated as

13 well as the duration of their participation. The amount of time spent in each activity was

14 summed over the week to obtain a single score representing the amount of PA performed

15 by each parent. A one-month test-retest procedure conducted with 20 parents revealed

16 satisfactory reliability for this measure ( $r=.82$ and .85 , respectively for father and mother).

17 Procedure

18 Agreement was obtained from both parents and from the school director for the

19 children's participation in the study and verbal assent was obtained from each child prior to

20 their involvement. Data were collected at two times over a one-year period (October 2000

21 and October 2001) from (1) questionnaires completed by parents and children, (2) and

22 from semi-structured interviews with children to obtain the PA information. In October

232000 , data for all of the parents' variables and child's age, sex and initial perceptions of

24 competence were obtained. One year later, child's physical activity and current perceptions

25 of competence were measured. Children completed questionnaires in the classroom in a 
1 small group with an assistant reading the questions and providing assistance to them. The

2 parents' questionnaire was given to the children, completed at home by the parents, and

3 then returned to the school a week later.

4 Data analysis

Descriptive statistics were obtained and preliminary data analyses were conducted

6 to investigate possible gender differences across the variables of interest. To test for

7 anticipated relationships among the variables in the full model, we adopted Anderson and

8 Gerbing's (1988) two-step modelling approach intended to identify sources of poor overall

9 model fit. On the first step, a confirmatory factor analysis (CFA) was conducted to test for

10 the construct validity of the latent variables. Once the factor structure was supported, the

11 second step involved a test of the relationships hypothesized in the theoretical model.

12 Alternative models were tested in which the direct influence of parental perceptions of the child's competence on child's PA involvement was added.

Results

Descriptive Statistics and Preliminary Analyses

Means and standard deviations for all the variables are presented separately for boys and girls in Table 1. Boys presented higher scores than girls on perceived competence at Time $1\left(F(1,150)=5.08, p<.05, \eta^{2}=.03\right)$, perceived competence at Time $2(F(1,150)$

$\left.19=3.85, p<.05, \eta^{2}=.03\right)$, and on parents' reports of their child's PA levels $(F(1,150)=$ 4.02, $p<.05, \eta^{2}=.03$ ). No other gender differences were found. To test whether parents'

21 beliefs concerning their child's competence in PA varied as a function of their own or their 22 child's gender, a 2 (child's sex) $\times 2$ (mother's and father's belief concerning their child's competence) analysis of variance was conducted, with repeated measure on the last variable. Neither main effects nor significant interactions were revealed from this analysis 
$1 \quad(p>.19)$. This finding indicates that mothers' and fathers' appraisals of their child's

2 competence did not significantly differ and did not vary with the gender of the child.

3 Confirmatory Factor Analysis

CFA was conducted to examine the construct validity of all of the model's latent

5 variables. Items on each subscale were aggregated randomly to form two composite scores

6 for each construct in order to reduce the number of variables and to keep the model degrees

7 of freedom reasonable (Bentler, 1980; Byrne, 1994). Given the difficulty in precisely

8 measuring the child's PA (see Sallis \& Saelens, 2000), we decided to use a latent

9 representation of this variable based both on parents' and children's report $(r=.46, p<$

$.001)$. As a result, the CFA was based on ten observed variables and five latent factors

11 (child's perceived competence at Time 1 and Time 2, mothers' and fathers' perceptions of child competence and child's PA). The analysis was conducted with LISREL 8.3 with the maximum likelihood method of estimation. In view of the current controversy regarding measures of overall goodness of fit, it is generally considered appropriate to report multiple indices (Bollen, 1989). Thus, the chi-square statistic, the goodness-of-fit index (GFI), the non-normed fit index (NNFI), the comparative fit index (CFI) and the standardized root mean square residual (SRMR) all were used to evaluate the adequacy of the fit of the model to the data. For GFI, NNFI and CFI values above .95 are considered satisfactory. For SRMR, values below 08 indicate a good fit of the model to the data. The first run of the analysis resulted in an inadequate fit of the model to the data $\left(\chi^{2}(25, N=152)=67.65, p<.001, \mathrm{GFI}=.92, \mathrm{NNFI}=.85, \mathrm{CFI}=.92, \mathrm{SRMR}=.067\right)$

LISREL output analysis revealed large residuals between manifest indicators of mothers' and fathers' perceptions of their child's physical competence, and between the first indicator of the child's perceived competence at Time 1 and Time 2. As mothers and fathers answered the same questions, and as they certainly share similar views on their 
1 child's competence, it is not surprising that manifest indicators of mothers' and fathers'

2 perceptions of their child's competence are correlated. Therefore, in accordance with

3 recommendations by Jöreskog and Sörbom (1996), two covariance errors were added

4 between these two pairs of variables. A third large residual remained between the first

5 indicator of child's perceived physical competence at Time 1 and Time 2 (i.e., between the

6 same indicator assessed at Time 1 and Time 2). As recommended in longitudinal designs

7 with auto-regressive effects (Jöreskog \& Sörbom, 1996), a third covariance error was

8 added between these two variables. This new model was run and provided a good fit to the

$9 \quad$ data $\left(\chi^{2}(22, N=152)=28.95, p>.05, \mathrm{GFI}=.96, \mathrm{NNFI}=.97, \mathrm{CFI}=.99, \mathrm{SRMR}=.04\right)$.

10 All $\lambda$ s were significant $(t>2.00)$. The computed reliabilities ${ }^{1}$ for the constructs were .63

11 for child PA, .69 and .77 for children's perceived physical competence at Time 1 and Time

122 , and .78 and .82 for mothers' and fathers' perceptions of their child's ability,

13 respectively. Thus, the variables demonstrated adequate construct validity.

\section{$14 \quad$ Structural model}

The second step of our analysis consisted of testing simultaneously the structural and measurement models (from the CFA analysis) thus allowing us to focus on conceptual connections among the variables of the model displayed in Figure 1 (the five latent factors plus mother's PA, father's PA, child's sex and child's age, considered as manifest variables). This resulted in a model with fourteen observed variables and five latent factors. Table 2 shows the covariance matrix used as input.

The hypothesized model provided a good fit to the data $\left(\chi^{2}(47, N=152)=59.44, p\right.$ $>.05, \mathrm{GFI}=.95, \mathrm{NNFI}=.95, \mathrm{CFI}=.97, \mathrm{SRMR}=.05$ ). The relation between mothers' $\mathrm{PA}$ and their children's PA was significant $(\beta=.30, p<.01)$ whereas fathers' PA did not

24 predict their child's PA involvement after controlling for the child's age $(\beta=.37, p<.001)$ and $\operatorname{sex}(\beta=-.02, p>.05)$. Similarly, mothers', but not fathers', perceptions of their child's 
1 ability significantly predicted the child's perceptions of their physical competence $(\beta=.41$,

$2 p<.01)$, independent of the child's age $(\beta=-.25, p<.01)$, sex $(\beta=-.31, p<.01)$, and the

3 child's initial level of perceived physical ability at Time $1(\beta=.09, p>.05)$. Eventually,

4 children's perceived physical competence predicted their PA level $(\beta=.48, p<.001)$.

A second model was tested in order to examine the possibility that parents'

6 perceptions have direct effects on child's PA. Paths from both fathers' and mothers'

7 perceptions of the child's competence to the child's PA were freely estimated, along with

8 the other path from the former model. This alternative model had a good fit to the data

$\left(\chi^{2}(45, N=152)=50.27, p>.05, \mathrm{GFI}=.96, \mathrm{NNFI}=.98, \mathrm{CFI}=.99, \mathrm{SRMR}=.04\right)$, but

was significantly different from the first model $\left(\Delta \chi^{2}(2)=9.17, p<.01\right)$. The direct path

from fathers' perceptions to child PA level was significant $(\beta=.35, p<.05)$ whereas the

influence of mothers' perceptions on this variable was not $(\beta=.01, p>.05)$. Adding these

paths did not significantly affect the size of the other paths in the first model. Finally, a

third model was tested in which the non-significant path between mothers' perceptions and child PA was removed. The fit of the model was $\operatorname{good}\left(\chi^{2}(46, N=152)=50.28, p>.05\right.$,

$\mathrm{GFI}=.96, \mathrm{NNFI}=.98, \mathrm{CFI}=.99, \mathrm{SRMR}=.04)$, and was not significantly different from the second model $\left(\Delta \chi^{2}(1)=.01, p>.05\right)$. Given the equivalence of the two alternative models, the simpler model was preferred. The structural coefficients of this model are displayed in Figure 2. Collectively, the variables within the model explained $30 \%$ of the variance in children's perceptions of their physical ability and $51 \%$ of the variance in children's PA level.

Discussion

Given the importance of PA for the long-term health and psychosocial development of children (e.g., Martinsen \& Stephens, 1994; Weiss \& Duncan, 1997), this study 
1 investigated the role of social and psychological factors in shaping children's physical

2 activity behaviour. With regard to social forms of influence, both parental role modelling

3 of PA and parental beliefs about their child's physical competence were examined in

4 relation to their influence upon children's perceived physical competence and PA levels.

5 These relationships were studied over a 12-month period to better tease out the role of

6 parental socialization influence as it shapes children's perceptions and behaviour over time.

7 Three significant findings emerged. First, evidence was found for the existence of

8 direct parental socialization influences on their child's involvement in PA through PA role

9 modelling effects. Second, support was obtained for the influence of parents' beliefs in that

10 mothers' perceptions of their child's physical competence were related to children's

11 perceived competence, and subsequent time spent in physical activity. Third, the findings

12 supported the link between children's perceptions of their physical competence and their

13 involvement in physical activity. The discussion focuses on each of these three major

14 findings as well as upon age and gender effects.

15 Parental role modelling effects

16 Mothers', but not fathers', involvement in PA was related to their child's

17 involvement in PA, and this finding provides partial support for the role modelling

18 hypothesis. It appears that mothers' role modelling behaviour seems to be more salient to

19 children in this age range than does the role modelling behaviour of their fathers. Previous studies using self-report measures of PA have generally found non significant or weak

21 correlations between parents' and children's PA levels (Dempsey et al, 1993; Kimiecik \&

22 Horn, 1998) whereas studies using more objective assessment, such as those with Caltrac

23 accelerometers, have found a moderate-to-strong relation between parent and child PA

24 levels (Freedson \& Evenson, 1991; Moore et al, 1991). Perhaps the methodological

25 precautions taken in our study (a latent representation of children's PA using two 
1 indicators) are at the origin of the significant results found, in spite of the use of self-report

2 measurements.

With regard to the strength of mothers', as opposed to fathers' influence, this

4 finding is consistent with two previous studies. First, in a sample of competitive youth

5 swimmers, Power and Woolger (1994) found that mothers' role modelling was positively

6 associated with their child's level of enthusiasm for participating in the sport whereas

7 fathers' role modelling was not. Another study examining familial aggregation of PA

8 habits found that mothers' PA levels, but not fathers', were related to children's PA

9 participation (Sallis, Patterson, Buono, Atkins, \& Nader, 1988). The extent of maternal

10 influence identified in these three studies might be surprising to some, however, these

11 findings seem to indicate that mothers are salient socialization agents for children of this

12 age range perhaps because they are likely to be more involved in the day-to-day activity

13 choices of their children. Other studies should be conducted to further address this finding.

14 Moreover, it will be interesting in the future to assess other "qualitative" variables (e.g.,

15 enjoyment) related to parents' PA. For example, a mother or a father who is enthusiastic

16 about his/her PA is more likely to be imitated by children than the one who practises at the

17 same level but does not express positive sentiments (Brustad, 1996; Fredericks \& Eccles,

18 2004).

19 Parental beliefs influences

From Eccles' theoretical perspective, a primary form of parental socialization

21 influence occurs through the process whereby parental beliefs about children's aptitudes

22 shape children's own self-related perceptions and subsequent motivational and behavioural patterns. A fundamental purpose of the present study was to assess the relative extent of

24 parental belief influences in the physical domain where only a limited amount of research

25 (e.g. Bois et al., 2002; Brustad, 1993, 1996) has previously considered this form of parental 
1 socialization influence. To demonstrate the existence of an influence between parental

2 beliefs on children's PA behaviour it was necessary to establish that parents' perceptions of

3 their child's ability at Time 1 predicted their child's self-perception of ability at Time 2,

4 controlling for the child's initial self-perception of ability at Time 1 (McCallum \& Austin,

5 2000). Secondly, for parental beliefs to have merit as contributors to children's PA

6 behaviour, it was necessary to establish that children's self-perceptions of ability

7 subsequently predicted their physical activity.

Results demonstrated that mothers', but not fathers', perceptions of their child's competence predicted their child's perceived physical competence 12 months later. It should be noted that these results were independent of the child's initial level of perceived competence, child's age and child's sex. These results are consistent with two other studies in the academic domain (Eccles et al., 1983; McGrath \& Repetti, 2000) which found that mothers' achievement attitudes were stronger predictors of children's perceived academic competence than were fathers' achievement attitudes. In contrast, Felson and Reed (1986) found that both mothers' and fathers' perceptions of their child's competence were influential in predicting their child's perceived competence in both academic and sport domains. Felson and Reed's sample constituted a broader and older age range ( $4^{\text {th }}$ to $7^{\text {th }}$ grade) than in the present study and utilized a cross-sectional design. Similar to other studies (e.g., McGrath \& Repetti, 2000), we speculate that our results could be attributed to the fact that mothers' socialization influence is greater with younger children due to their 21 extensive involvement in their child's daily activities.

Role of perceived competence in physical activity 
1 in regard to physical activity, the more likely they were to be engaged in this activity. This

2 result is consistent with other PA studies with children (e.g., Dempsey et al., 1993; Eccles

3 \& Harold, 1991; Kimiecik et al., 1996). As our results also highlight the influence of

4 mothers' competence beliefs upon children's beliefs about their own competence, it can be

5 argued that mothers indirectly affect their children's physical activity involvement in this

6 manner.

$7 \quad$ For fathers, a direct relationship was found between fathers' perceptions of their

8 child's physical competence and the child's PA. This finding suggests that fathers'

9 perceptions affect their child's PA via other variables. Eccles et al. (2000) hypothesized

10 that parents' perceptions could affect the nature, and the frequency, of opportunities for

11 their children to play sport. On the other hand, the Eccles et al. model (e.g., Wigfield \&

12 Eccles, 2000) postulates that children's involvement in achievement activities is predicted

13 both by children's self-perceptions and by the value they attribute to the activity.

14 Therefore, fathers' perceptions can affect their child's PA either directly by giving him/her

15 more or less opportunities to play sport, or indirectly via the child's values toward PA.

16 Further studies including the variable of value are needed and certainly constitute a

17 promising area of investigation.

18 Interestingly, our study suggests that mothers and fathers have distinct patterns of

19 influence. Mothers' influence seems to occur through role modelling and through the

20 influence of their beliefs about the child's physical competence, whereas the fathers'

21 influence suggests the existence of other processes. Further studies are necessary to obtain

22 a deeper understanding of the specific role played by mothers and fathers in shaping their

23 child's involvement in PA.

24 Gender differences 
Consistent with other studies (e.g., Eccles \& Harold, 1991; Jacobs \& Eccles, 1992),

2 our results revealed gender differences in children's perceived competence at Time 1 and

3 Time 2. In addition, parents of boys reported higher levels of PA for their child than did

4 parents of girls. It was hypothesized in previous studies (e.g. Jacobs \& Eccles, 1992) that

5 gender differences in children's perception of competence could be due to parents' gender

6 stereotyped perceptions. If parents' perceptions of their child's physical competence are

7 higher for boys than for girls, the influence of parental beliefs could explain gender

8 differences in children's own self-perceptions of physical competence. However, our

9 results demonstrated that mothers' and fathers' estimations of their child's ability did not

10 vary as a function of the child's gender. Our findings are consistent with Kimiecik and

11 Horn (1998) who found that neither mothers nor fathers held gender-differentiated

12 perceptions of their child's physical competence. However, the existence of parental gender stereotyped perceptions should not be dismissed because stereotypes were not directly assessed in this study. Moreover, the measurement used in this study without any reference to an objective performance can mask the occurrence of gender stereotypes.

16 Indeed according to the shifting standards model (Biernat, 1995), individuals can adjust the

17 meaning of the subjective scales according to their appraisal for men and women regarding height, weight and competence, which removes evidence of gender stereotypes. To uncover those differences and to more assess parents' true mental representation of children, future research could use scales that are explicitly linked to an external anchor 21 and/or direct parents' gender stereotypes. Despite the fact that we have taken into account the influence of both mothers' and fathers' beliefs, as well as the child's age, sex, and initial level of perceived competence, our model explained only $30 \%$ of the variance in children's self-perceptions of competence. This could suggest (1) that other socializing agents, notably peers, siblings, 
1 teachers, and coaches are likely to be instrumental in shaping children's self-perceptions at

2 this age (see Weigand, Carr, Petherick, \& Taylor, 2001); (2) and that children utilize many

3 additional sources of information in assessing their competence, particularly personal

4 sources, such as the relative ease with which they learn new skills and their perceived rate

5 of improvement in sports and activities (Horn, 2004). Consequently, future studies should

6 address the influence of other socializing agents and varied sources of competence

7 information in addressing children's competence perceptions.

9 longitudinal data, our results remain correlational in nature and hence causality can only be

10 inferred cautiously. Secondly, it is likely that the direct relationships between parents' and

11 children's variables constitute only a first step in understanding how parents impact

12 children's PA characteristics. For example, several mediators omitted in this study could be

13 involved in the relation between parents' perceptions of their child's competence and

14 children's own self-perceptions or physical activity. These might include the respective

15 roles of children's values, perceptions of parents' beliefs (i.e., reflected appraisal), as well

16 as parents' behaviours (e.g., extent of encouragement, provision of athletic opportunities

17 and equipment ), and parents' affective orientations toward physical activity (enjoyment).

18 All merit consideration in future studies. Third, the relationship between children's

19 perceived competence and PA levels may be bi-directional. It is logical to assume that

20 children's PA involvement should impact their self-perceptions of competence in this

21 domain just as competence perceptions are likely to affect involvement. Therefore, the

22 relation between these variables should be interpreted cautiously. Finally, it is important to

23 note that our sample was limited to children with both their mothers and fathers in the

24 home. Consequently those results are likely to be limited to this type of family. A related 
1 limitation pertains to the fact that as parents completed their questionnaires, it is possible

2 that on some occasions the mother and the father may have completed them together. Overall, this study has contributed in several ways to the literature on the

4 socialization of children's physical activity. The results from this study provide further

5 evidence for the need to examine the specific influence of fathers and mothers, as opposed

6 to considering parental influence collectively. More specifically, our results showed that

7 mothers', but not fathers', involvement in PA predicted their children's involvement in

8 physical activity. In addition mothers', but not fathers', perceptions of their child's

9 physical competence was related to the child's own self-appraisal of competence, after

10 controlling for the child's initial level of perceived competence. However, fathers'

11 perceptions directly predicted their child's physical activity. An additional important

12 outcome from the study was the relationship between perceived physical competence and

13 PA involvement. Clearly, enhancing children's perceived physical competence should be a

14 goal for practitioners interested in facilitating physical activity. A particular contribution

15 was the recognition that parents can affect their children's PA involvement in direct and

16 indirect manners through role modelling and parental belief influences. Insofar as there is

17 no reason to suspect cultural differences between France and other industrialized countries

18 regarding socialization into sport, we think that these results can generalize to the other

19 western industrialized countries where previous studies have been conducted.

20 Nevertheless, cross-cultural studies are needed to further investigate those questions. 
2 Anderson, J. C., \& Gerbing D. W. (1988). Structural equation modeling in practice: A review and recommended two-step approach. Psychological Bulletin, 103, 411-423.

Babkes, M. L., \& Weiss, M. R. (1999). Parental influence on children's cognitive and affective responses to competitive soccer participation. Pediatric Exercise Science, $11,44-62$.

Bandura, A. (1986). Social foundations of thought and action: A social cognitive theory. Englewood Cliffs, NJ: Prentice Hall.

Bandura, A. (1997). Self-efficacy: The exercise of control. New York: W.H. Freeman.

Baranowski, T. (1988). Validity and reliability of self-report of physical activity: An information processing perspective. Research Quarterly for Exercise and Sport, 59, 314-327.

Baron, R. M., \& Kenny, D. A. (1986). The moderator-mediator variable distinction in social psychological research: Conceptual, strategic, and statistical consideration. Journal of Personality and Social Psychology, 51, 1173-1182.

Bentler, P. M. (1980). Multivariate analysis with latent variables: Causal modeling. Anmual Review of Psychology, 31, 419-456.

Biernat, M. (1995). The shifting standards model: Implications of stereotype accuracy for judgement. In Y.T. Lee, L. Jussim, \& C.R. McCauley (Eds.). Stereotype accuracy: Toward appreciating groups differences (pp. 87-114). Washington, DC: APA.

Bois, J. E., Sarrazin, P. G., Brustad, R. J., Trouilloud, D. O., \& Cury F. (2002). Mothers' expectancies and young adolescents' perceived physical competence: A year long study. Journal of Early Adolescence, 22, 384-406.

Bollen, D. A. (1989). Structural equations with latent variables. New York: Wiley. 
1 Brislin, R.W. (1986). The wording and translation of research instruments. In W. Lonner \& J. Berry (Eds.), Field methods in cross-cultural research (pp. 137-164). Beverly Hills, CA: Sage.

Brustad, R. J. (1992). Integrating socialization influences into the study of children's motivation in sport. Journal of Sport \& Exercise Psychology, 14, 59-77.

Brustad, R. J. (1993). Who will go out and play? Parental and psychological influences on children's attraction to physical activity. Pediatric Exercise Science, 5, 210-223.

Brustad, R. J. (1996). Attraction to physical activity in urban schoolchildren: Parental socialization and gender influences. Research Quarterly for Exercise and Sport, 67, 316-323.

Brustad, R. J., Babkes, M. L., \& Smith, A. L. (2001). Youth in sport: Psychological considerations. In R. N. Singer, H. A. Hausenblas, \& C. M. Janelle (Eds.) Handbook of Sport Psychology, (2 ${ }^{\text {nd }}$ Ed., pp. 604-635). New York: Wiley.

Byrne, B. (1994). Structural equation modeling with EQS and EQS/Windows. Thousand Oaks, CA: Sage.

Dempsey, J. M., Kimiecik, J. C., \& Horn, T. S. (1993). Parental influence on children's moderate to vigorous physical activity participation: An expectancy-value approach. Pediatric Exercise Science, 5, 151-167.

Eccles, J. S., Adler, T. F., Futterman, R., Goff, S. B., Kaczala, C. M., Meece, J. L., \& Midgley, C. (1983). Expectancies, values, and academic behaviors. In J.T. Spence (Ed.), Achievement and achievement motivation (pp. 75-146). San Francisco, CA: Freeman.

Eccles J. S., \& Harold, R. D. (1991). Gender differences in sport involvement: Applying the Eccles' expectancy-value model. Journal of Applied Sport Psychology, 3, 7-35. 
1 Eccles J. S., Wigfield, A., \& Schiefele, U. (1998). Motivation to succeed. In W. Damon (Series Ed.) \& N. Eisenberg (Vol. Ed.), Handbook of child psychology: Vol. 3 Social, emotional and personality development (5 ${ }^{\text {th }}$ ed., pp. 1017-1094). New York: Wiley.

Felson, M. B., \& Reed, M. (1986). The effect of parents on the self-appraisals of children. Social Psychology Quarterly, 49, 302-308.

Fredericks, J.A., \& Eccles, J.S. (2004). Parental influences on youth involvement in sports. In M.R. Weiss (Ed.), Developmental sport and exercise psychology: a lifespan perspective (pp. 144-164). Morgantown, WV: Fitness Information Technology.

Freedson, P. S., \& Evenson, S. (1991). Familial aggregation in physical activity. Research Quarterly for Exercise and Sport, 62, 384-389.

Gollob, H. F., \& Reichardt, C. S. (1991). Interpreting and estimating indirect effects assuming time lags really matter. In L. M. Collins \& J. L. Horn (Eds.), Best methods for the analysis of change (pp. 243-259). Washington, DC: American Psychological Association.

Greendorfer, S. L. (1992). Sport socialization. In T. S. Horn (Ed.), Advances in sport psychology (pp. 201-218). Champaign, IL: Human Kinetics.

Haaro, M. (1997). Validation of a questionnaire to assess physical activity of children ages 4-8 years. Research Quarterly for Exercise and Sport, 68, 259-268.

Harter, S. (1981). The development of competence motivation in the mastery of cognitive and physical skills: Is there a place for joy? In G.C. Roberts \& D.M. Landers (Eds.), Psychological of Motor Behavior and Sport-1980 (pp. 3-29). Champaign, IL: Human Kinetics.

Harter, S. (1985). Manual for the self-perception profile for children. Denver, CO: University of Denver Press. 
1 Horn, T.S. (2004). Developmental perspectives on self-perceptions in children and adolescents. In M.R. Weiss (Ed.), Developmental sport and exercise psychology: a lifespan perspective (pp. 101-143). Morgantown, WV: Fitness Information Technology.

Jacobs, J. E., \& Eccles, J. S. (1992). The impact of mothers' gender role stereotypic beliefs on mothers' and children's ability perceptions. Journal of Personality and Social Psychology, 63, 932-944.

Jacobs, J. E., Lanza, S., Osgood, D. W., Eccles, J. S., \& Wigfield, A. (2002). Changes in children's self-competence and values: Gender and domain differences across grades one through twelve. Child Development, 73, 509-527.

Jöreskog, K., \& Sörbom, D. (1996). LISREL 8: User's reference guide; Chicago: SSI Inc.

Kimiecik, J. C., \& Horn, T. S. (1998). Parental beliefs and children's moderate-to-vigorous physical activity. Research Quarterly for Exercise and Sport, 69, 163-175.

Kimiecik, J. C., Horn, T. S., \& Shurin, C. S. (1996). Relationships among children's beliefs, perceptions of their parents' beliefs and their moderate to vigorous physical activity. Research Quarterly for Exercise and Sport, 67, 324-336.

MacCallum, R. C., \& Austin, J. T. (2000). Applications of structural equation modeling in psychological research. Anmual Review of Psychology, 51, 201-226.

McCullagh, P., Matzkanin, K., Shaw, S. D., \& Maldonado, M. (1993). Motivation for participation in physical activity: Comparison of parent-child perceived competence and perceived motives. Pediatric Exercise Science, 5, 224-233.

McGrath, A. P., \& Repetti, R. L. (2000). Mothers' and fathers' attitudes toward their children's academic performance and children's perceptions of their academic competence. Journal of Youth and Adolescence, 26(6), 713-723. 
1 Manios, Y., Kafatos, A., \& Markakis, G. (1998). Physical activity of 6-year old children:

$2 \quad$ Validation of two proxy reports. Pediatric Exercise Science, 10, 176-188.

3 Martinsen, E. W., \& Stephens, T. (1994). Exercise and mental health in clinical and free living populations. In R. K. Dishman (Ed), Advances in exercise adherence (52-72). Champaign, IL: Human Kinetics.

Moore, L. L., Lombardi, D. A., White, M. J., Campbell, J. L., Oliveira, S. A., \& Ellison, R C. (1991). Influence of parents' physical activity levels on activity levels of young children. Journal of Pediatrics, 118, 215-219.

Parsons, J., Adler, T., \& Kaczala, C. (1982). Socialization of achievement attitudes and perceptions: Parental influences. Child Development, 53, 310-329.

Power, T. G., \& Woolger, C. (1994). Parenting practices and age-group swimming: A correlational study. Research Quarterly for Exercise and Sport, 65(1), 59-66.

Sallis, J. F., Buono, M. J., Roby, J. J., Micale, F. G., \& Nelson, J. A. (1993). Seven-day recall and other physical activity self-reports in children and adolescents. Medicine and Science in Sports and Exercise, 25, 99-108.

Sallis, J. F., \& Hovell, M. R. (1990). Determinants of exercise behavior. Exercise and Sport Sciences Reviews, 18, 307-330.

Sallis, J. F., Patterson T. L., Buono, M. J., Atkins, C. J., \& Nader, P. R. (1988). Aggregation of physical activity habits in Mexican-American and Anglo families. Journal of Behavioral Medicine, 11, 31-41.

Sallis, J. F., \& Saelens, B. E. (2000). Assessment of physical activity by self-report: Status, limitations, and future directions. Research Quarterly for Exercise and Sport, 71, 114. 
1 Sallis, J. F., Simons-Morton, B. G., Stone, E. J., Corbin, C. B., Epstein, L. H., Faucette, N., et al. (1992). Determinants of physical activity and interventions in youth. Medicine and Science in Sports and Exercise, 24, S248-S257.

Sarrazin, P., Bois, J., \& Trouilloud, D. (2000a). Trans-cultural validation of the Harter (1985) Perceived Physical Competence Scale for Children. Unpublished manuscript, Université J. Fourier, Grenoble I, France

Sarrazin, P., Bois, J., \& Trouilloud, D. (2000b). Trans-cultural validation of the measurement scales of the Eccles et al. (1983) expectation-valence model. Unpublished manuscript, Université J. Fourier, Grenoble I, France.

Suter, E., \& Hawes, M. R. (1993). Relationship of physical activity, body fat, diet, and blood lipid profile in youths 10-15 yrs. Medicine and Science in Sports and Exercise, 25, 748-754.

Weigand, D. A., Carr, S., Petherick, C., \& Taylor, A. (2001). Motivational climate in sport and physical education: The role of significant others. European Journal of Sport Science, 1(4). Available at $<$ www.humankinetics.com/ejss $>$.

Weiss, M. R., \& Duncan S. C. (1997). The relationship between physical competence and peer acceptance in the context of children's sports participation. Journal of Sport \& Exercise Psychology, 14, 177-191.

Weiss, M. R., \& Ebbeck, V. (1996). Self-esteem and perceptions of competence in youth sport: Theory, Research, and enhancement strategies. In O. Bar-Or (Ed.), The Encyclopedia of sports medicine, Vol. V: The child and adolescent athlete (pp. 364382). Oxford: Blackwell.

Wigfield, A., \& Eccles, J. S. (2000). Expectancy-value theory of achievement motivation. Contemporary Educational Psychology, 65, 68-81. 
Parental influence on physical activity 29

2

3 1. Reliability estimates for the total scales are obtained by (Bollen, 1989) the following

4 equation: $\rho=(\Sigma \lambda i)^{2} /\left((\Sigma \lambda i)^{2}+\Sigma \delta\right.$ ii) where $\lambda \mathrm{i}$ are the factor loading and $\delta$ ii the error

5 variances. 
Table 1

Means and standard deviations for parent and child variables

\begin{tabular}{lccccc}
\hline & \multicolumn{2}{c}{ Boys } & & \multicolumn{2}{c}{ Girls } \\
\cline { 2 - 3 } \cline { 5 - 6 } Variable & $M$ & $S D$ & & $M$ & $S D$ \\
\hline $\begin{array}{l}\text { Child's self report of physical } \\
\text { activity }\end{array}$ & 1.77 & 1.32 & & 1.56 & 1.23 \\
$\begin{array}{l}\text { Parent's report of child's } \\
\text { physical activity }\end{array}$ & 3.17 & 1.9 & & 2.51 & 2.06 \\
$\begin{array}{l}\text { Child's perceptions of } \\
\text { physical competence (Time1) }\end{array}$ & 3.41 & 0.57 & & 3.17 & 0.68 \\
$\begin{array}{l}\text { Child's perceptions of } \\
\text { physical competence (Time2) }\end{array}$ & 3.18 & 0.50 & & 2.98 & 0.71 \\
$\begin{array}{l}\text { Mother's self-report of } \\
\text { physical activity }\end{array}$ & 1.20 & 1.77 & & 0.87 & 1.42 \\
$\begin{array}{l}\text { Mother's perceptions of their } \\
\text { child's competence }\end{array}$ & 3.36 & 0.69 & & 3.47 & 0.60 \\
$\begin{array}{l}\text { Father's self-report of } \\
\text { physical activity }\end{array}$ & 1.81 & 2.00 & & & \\
$\begin{array}{l}\text { Father's perceptions of their } \\
\text { child's competence }\end{array}$ & 3.35 & 0.71 & 3.50 & 0.64 \\
\hline
\end{tabular}




\section{Table 2}

Covariance matrix used in Figure 2

\begin{tabular}{|c|c|c|c|c|c|c|c|c|c|c|c|c|c|c|}
\hline Variables & 1 & 2 & 3 & 4 & 5 & 6 & 7 & 8 & 9 & 10 & 11 & 12 & 13 & 14 \\
\hline 1. Age & .71 & & & & & & & & & & & & & \\
\hline 2. Sex & -.06 & 1 & & & & & & & & & & & & \\
\hline 3. PRPA & .35 & -.41 & 4.04 & & & & & & & & & & & \\
\hline 4. CRPA & .21 & -.13 & 1.18 & 1.62 & & & & & & & & & & \\
\hline 5. PC1 & -.10 & -.16 & .03 & .14 & .68 & & & & & & & & & \\
\hline 6. $\mathrm{PC} 2$ & .01 & -.14 & .21 & .22 & .28 & .43 & & & & & & & & \\
\hline 7. $\mathrm{C} 1$ & -.11 & -.16 & .27 & .19 & .26 & .11 & .49 & & & & & & & \\
\hline 8. $\mathrm{C} 2$ & -.04 & -.09 & .29 & .19 & .14 & .11 & .30 & .51 & & & & & & \\
\hline 9. MPA & .02 & -.21 & .58 & .56 & .04 & .06 & .01 & .05 & 2.53 & & & & & \\
\hline 10. MP1 & .08 & .10 & .29 & .30 & .22 & .17 & .13 & .13 & .07 & .72 & & & & \\
\hline 11. MP2 & .07 & .03 & .28 & .15 & .12 & .09 & .12 & .10 & .08 & .31 & .31 & & & \\
\hline 12. FPA & -.14 & -.14 & .25 & .29 & .16 & .03 & .07 & -.20 & .57 & -.07 & -.12 & 4.77 & & \\
\hline 13. FP1 & .08 & .10 & .36 & .25 & .19 & .17 & .06 & .16 & -.03 & .43 & .22 & -.10 & .73 & \\
\hline 14. FP2 & .07 & .08 & .34 & .23 & .13 & .10 & .08 & .12 & .01 & .24 & .20 & -.01 & .36 & .38 \\
\hline
\end{tabular}

Note: PRPA = Parent's report of child's physical activity; CRPA $=$ Child's self-report of physical activity; PC $=$ Child's perceived competence 1 for index 1, 2 for index 2 (at Time 1); C = Child's perceived competence (at Time2); MPA = Mother's physical activity; FPA = Father's physical activity; MP = Mother's perception of child's competence in physical activity; FP = Father's perception of child's competence in physical activity 


\section{Figure Captions}

Figure 1 : Conceptual model of mothers' and fathers' influences on their child's physical activity. The double lines convey the hypothesis of the parental beliefs influence, the dotted lines convey the hypothesis of the modelling effect, and the thin lines convey the variables of control

Figure 2 : Structural equation model of mothers' and fathers' influences on their children perceived competence and physical activity. Standardized solutions are presented. ${ }^{*} p<.05$. $* * p<.01 . * * * p<.001$ 


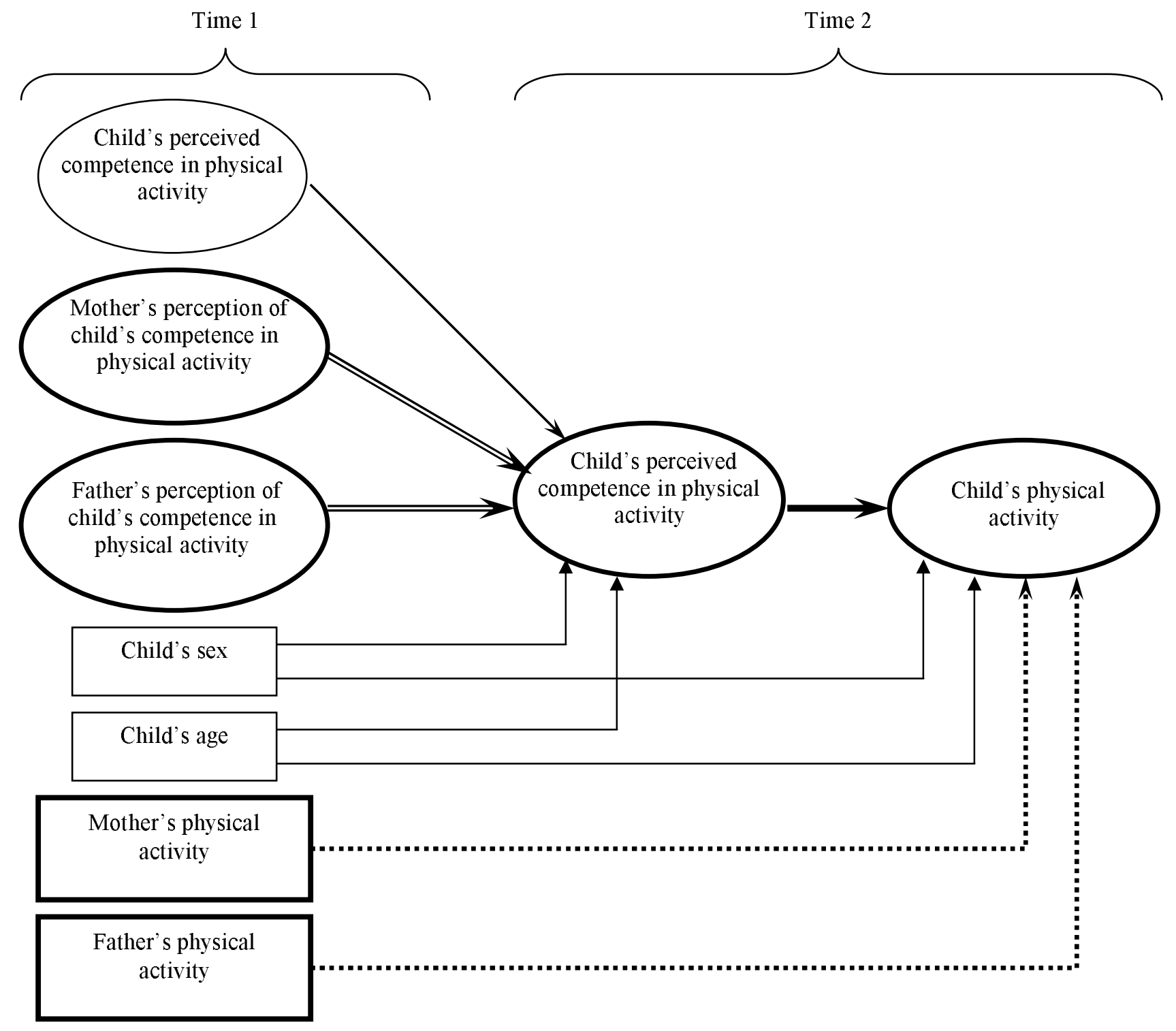




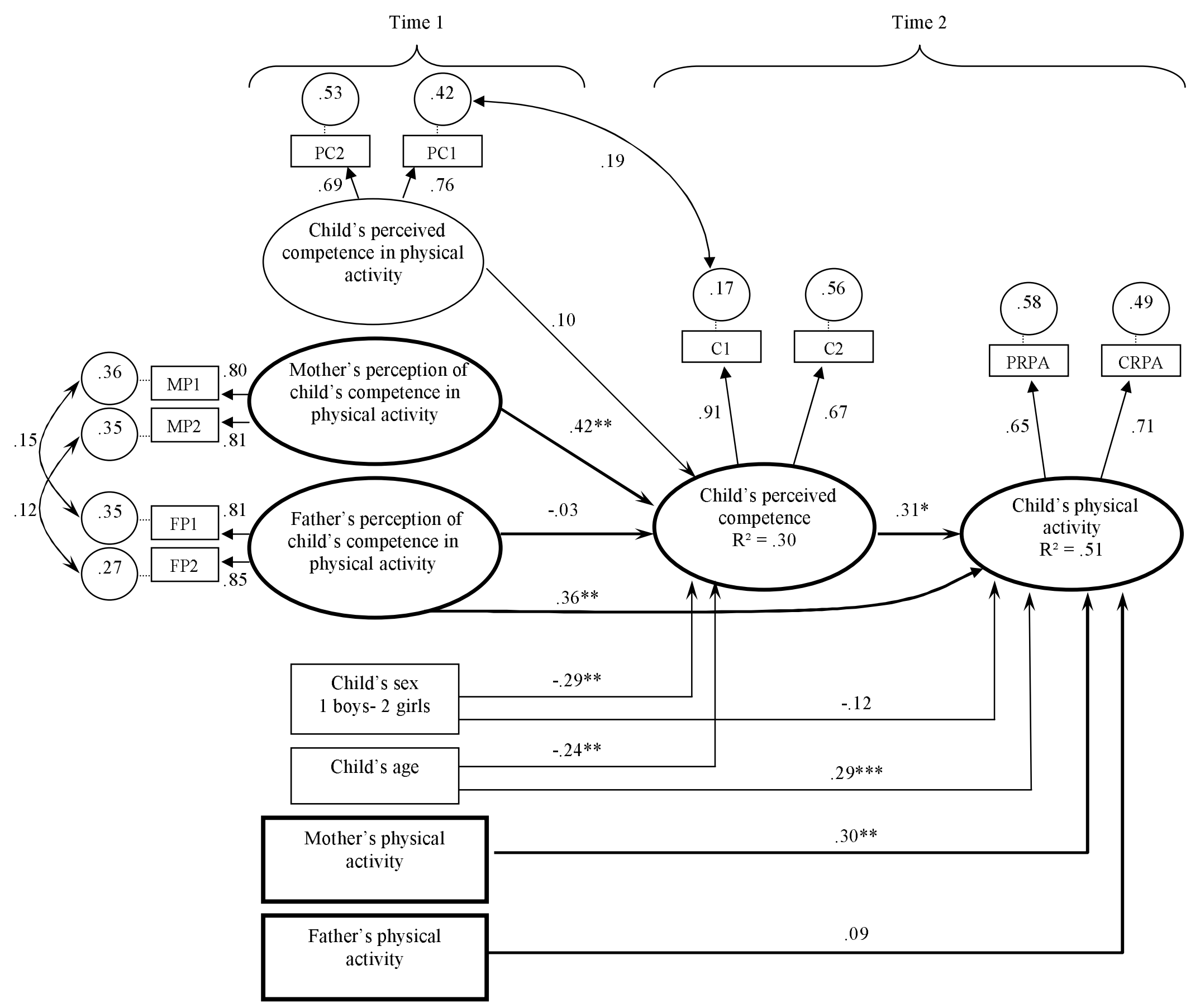

